\title{
The Relationship Between Angiotensin Converting Enzyme Gene Polymorphism, Coronary Artery Disease, and Stent Restenosis
}

\section{The Role of Angiotensin Converting Enzyme Inhibitors in Stent Restenosis in Patients With Diabetes Mellitus}

\author{
Sema Guneri, ${ }^{1}$ FESC, Nezihi BARIS, ${ }^{1}$ MD, Deniz Aytekin, ${ }^{1}$ MD, \\ Bahri AKdenIz, ${ }^{1} \mathrm{MD}$, Nihat PEKEL, ${ }^{1} \mathrm{MD}$, and Volkan BozdemiR, ${ }^{1} \mathrm{MD}$
}

\section{SUMMARY}

Patients with diabetes mellitus (DM) have advanced atherosclerosis compared with nondiabetics. Restenosis after intracoronary stent implantation occurs frequently in diabetic patients. Angiotensin II is an important growth factor for the development of neointimal hyperplasia after vascular injury. The aim of our study was to evaluate the relationships between angiotensin converting enzyme (ACE) gene insertion/deletion (I/D) polymorphism and coronary artery disease (CAD) and stent restonosis in diabetic patients.

One hundred and thirty consecutive patients with CAD and 47 consecutive patients (14 males, mean age, $58.0 \pm 10.0$ ) without CAD were enrolled in the study. All patients had type 2 (noninsulin dependent) DM. The patients with CAD underwent percutaneous transluminal coronary angioplasty (PTCA) and stenting. Ninety-four (59 males, mean age, $60.3 \pm 9.8)$ underwent control coronary angiography at the end of the follow-up period (mean duration, $9.1 \pm 2.9$ months). ACE gene I/D genotyping was identified in all patients.

No significant difference was found among patients with and without CAD with respect to ACE gene I/D polymorphism $(P=0.460)$. In the control coronary angiography, stent restenosis and new lesion development were comparable in each genotyping subgroup. However, a significant relationship was observed between restenosis and the use of ACE inhibitors (ACEI) in patients with D allele (ACEI ratio, $43.5 \%$ in the restenosis group and 56.5\% in non-restenotic group, $P<0.05$ ).

We did not find any relationship between ACE gene I/D polymorphism and CAD and stent restenosis and new lesion development in diabetic patients. On the other hand, ACEI treatment may reduce stent restenosis in type 2 diabetic patients with $\mathrm{D}$ allele (DD or ID). (Int Heart J 2005; 46: 889-897)

Key words: DD genotype, Stent restenosis, ACEI treatment, Diabetics

From the ${ }^{1}$ Department of Cardiology, School of Medicine, Dokuz Eylul University, Izmir, Turkey.

Address for correspondence: Nezihi Baris, MD, Dokuz Eylul University School of Medicine, Department of Cardiology 35340 Inciralti, Izmir, Turkey.

Received for publication February 14, 2005

Revised and accepted May 16, 2005. 
PATIENTS with diabetes mellitus (DM) commonly possess a cluster of coronary risk factors which explains the more advanced atherosclerosis commonly found in these patients compared with patients without DM. Consequently, in many centers, as many as $20 \%$ of patients undergoing a percutaneous coronary intervention have DM. ${ }^{1)} \mathrm{DM}$ has been repeatedly identified as an independent predictor of restenosis after both percutaneous transluminal coronary angioplasty (PTCA) ${ }^{2,3)}$ and coronary stenting. ${ }^{4,5)}$ In-stent restenosis (ISR) occurs after treatment of coronary artery stenosis in $12 \%$ to $32 \%$ of coronary interventions with stents. ${ }^{6}$ Restenosis after intracoronary stent implantation occurs more frequently in diabetic than in nondiabetic patients. ${ }^{7)}$

Angiotensin converting enzyme (ACE) stimulates smooth muscle cell proliferation, ${ }^{8)}$ and the plasma concentration of ACE is partly controlled by an insertion/deletion (I/D) polymorphism in the ACE gene on chromosome 17. ${ }^{9)}$ The I/D polymorphism is characterized by the presence (insertion) or absence (deletion) of a 288-base pair alu repeat sequence within intron 16 on chromosome 17, which results in the following 3 genotypes: II and DD homozygotes and ID heterozygotes. Elevated levels of angiotensin II have been implicated in the development of neointimal hyperplasia after vascular injury. ${ }^{10)}$ The DD genotype of the ACE gene is associated with higher angiotensin II levels, ${ }^{9,11)}$ suggesting that carriers of the DD genotype might benefit from treatment with ACE inhibitors (ACEI) after stent placement in coronary arteries. Recently, the HOPE and EUROPA trials demonstrated that ACEI reduce the clinical outcomes of atherosclerosis. ${ }^{12,13)}$

The aim of the present study was to evaluate the relationship between ACE gene I/D polymorphism and coronary artery disease (CAD) in diabetic patients. The second aim was to evaluate the influence of ACE gene I/D polymorphism on stent restenosis in a diabetic population. The third aim was to investigate the genetic basis of the influence of ACEI on stent restenosis in patients with DM. To the best of our knowledge, ACE gene polymorphism, stent restenosis, and ACEI have not been studied in a diabetic group of patients in any trial.

\section{METHODS}

One hundred and thirty consecutive patients with CAD and 47 consecutive patients without $\mathrm{CAD}$ were enrolled in the study. All were fully informed about the procedure and informed consent was obtained from each. All patients had type 2 (noninsulin dependent) DM. DM was diagnosed according to the recommendations of the American Diabetes Association. ${ }^{14)}$ All patients underwent routine quantitative coronary angiography (QCA) for stable angina pectoris. None was characterized with acute coronary syndrome. Stenosis with a diameter of $50 \%$ or more in QCA was accepted as CAD. Elective PTCA and stent implanta- 
tion were performed in patients with $70 \%$ or higher diameter stenosis in major epicardial coronary arteries. All of the patients had coronary artery disease with stable angina. Coronary ischemia was verified with either electrocardiography or noninvasive stress tests. Only one kind of stent (Gendyl stent, Blue Medical) was used for this study. Mean inflation pressure and time were 10.2 $\pm 1.3 \mathrm{~atm}$ and 42.3 \pm 5.6 seconds, respectively. Postdilatation with a different balloon was not performed. Unfractionated heparin (70-100 U/kg) was administered only at the beginning of the procedure. Postprocedural pharmacological therapy consisted of aspirin (100 mg once daily) and clopidogrel (300 mg loading dose and $75 \mathrm{mg}$ once daily for nine months). Treatment with an ACEI was at the discretion of the attending physicians, who were unaware of the ACE genotype. Mean duration of follow-up was $9.1 \pm 2.9$ months. All patients underwent a physical examination and routine biochemical tests in the $1^{\text {st }}, 3^{\text {rd }}$ and $6^{\text {th }}$ months. In the $6^{\text {th }}$ month, a maximal exercise test was performed in all patients. Ninety-four patients agreed to undergo control coronary angiography. Thirty-six other patients, who did not agree, had no coronary ischemia in their exercise tests. Stent restenosis and the development of new lesions were investigated in control QCA. ISR was defined as $70 \%$ or greater stenosis in the stented segment. The criteria for a new lesion were: 1) absence in the first diagnostic QCA, 2) located in a different segment to that of the previous target lesion, and 3) $50 \%$ or greater stenosis.

ACE genotyping was performed by laboratory staff who were unaware of the clinical data. Genomic DNA was extracted from peripheral blood leukocytes. ACE genotypes were determined using a polymerase chain reaction, according to previously published protocols. ${ }^{15)}$ All tests and examinations were performed before genotyping.

Statistical analysis: Continuous variables are expressed as the mean \pm SD and their differences among genotypes were compared by a $t$-test and analysis of variance. The distribution of categorical variables among genotypes was compared using the chi-square test.

\section{RESULTS}

The mean age of all patients was $59.6 \pm 9.9$ years. The population was divided according to the presence or absence of CAD. Group 1 consisted of 94 patients (59 males, mean age, $60.3 \pm 9.8$ years) with CAD and control angiography to detect ISR. The mean percentage of diameter stenosis of coronary arteries in QCA was $82.5 \% \pm 7.8 \%$ in group 1 . Group 2 consisted of 47 patients (14 males, mean age, $58.0 \pm 10.0$ years) without CAD. There was no significant difference between two groups with respect to age $(P=0.19)$, however, the incidences of male gender, hypertension, hyperlipidemia, and a family history of 
Table I. Demographic Parameters and Risk Factors According to the Presence of CAD

\begin{tabular}{lccc}
\hline & Group 1 CAD $(+)(n=94)$ & Group 2 CAD (-) $(n=47)$ & $P$ \\
\hline Duration of DM (years) & $9.7 \pm 7.0$ & $6.6 \pm 4.4$ & 0.007 \\
HbA1c $(\mathrm{mg} / \mathrm{dL})$ & $6.4 \pm 1.2$ & $6.0 \pm 1.1$ & $\mathrm{NS}$ \\
BMI $\left(\mathrm{kg} / \mathrm{m}^{2}\right)$ & $27.4 \pm 3.0$ & $28.0 \pm 3.0$ & $\mathrm{NS}$ \\
Hypertension & $85(90 \%)$ & $31(65 \%)$ & $<0.01$ \\
Hyperlipidemia & $93(98 \%)$ & $31(65 \%)$ & $<0.01$ \\
Smoking & $53(56 \%)$ & $34(72 \%)$ & $\mathrm{NS}$ \\
Family history & $66(70 \%)$ & $20(42 \%)$ & $<0.01$ \\
\hline
\end{tabular}

DM indicates diabetes mellitus; HbA1c, oxidized hemoglobin; BMI, body mass index; and NS, not significant.

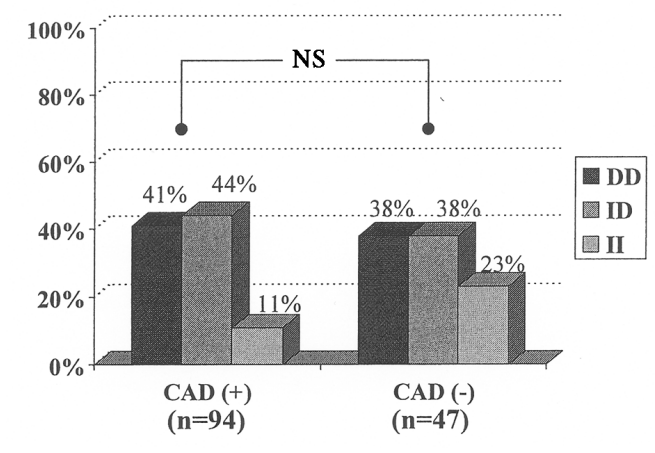

Figure 1. Relationship between $\mathrm{CAD}$ and genotypic subgroups.

CAD were significantly greater in group 1 than group $2(P<0.01)$. Similarly, the duration of diabetes was longer in group 1 than group 2 . The other demographic characteristics and risk factors of the two groups were comparable (Table I).

After genotyping, the patients were classified into three genotypic subgroups: DD, ID, and II. The frequencies of D and I allele were 0.62 and 0.38 , respectively. The genotype distribution obeyed the constraints of the HardyWeinberg equilibrium. No significant difference in genotypic subgroups was observed between groups 1 and 2 (Figure 1).

All patients with implanted stents who accepted the $6^{\text {th }}$ month control QCA were classified according to genotype. There were no significant differences between the three subgroups with respect to demographic parameters and risk factors (Table II). The properties of the target vessels and stents were similar for the three genotypic subgroups (Table III). In the $6^{\text {th }}$ month control QCA, stent restenosis was observed in $46(35.3 \%)$ of 130 patients who received a stent. The mean percentage of diameter restenosis was $67.8 \% \pm 8.3$ in these patients. When 
Table II. Demographic Properties and Risk Factors for Genotypic Subgroups in Patients With CAD

\begin{tabular}{lcccc}
\hline & DD $(n=39)$ & ID $(n=44)$ & II $(n=11)$ & $P$ \\
\hline Age (years) & $60.6 \pm 10.2$ & $60.1 \pm 9.8$ & $60.0 \pm 8.8$ & NS \\
Duration of DM (years) & $9.2 \pm 7.2$ & $10.1 \pm 7.2$ & $9.5 \pm 6.1$ & NS \\
Hypertension & $37(94 \%)$ & $38(86 \%)$ & $10(90 \%)$ & NS \\
Hyperlipidemia & $39(100 \%)$ & $44(100 \%)$ & $11(100 \%)$ & NS \\
Smoking & $26(66 \%)$ & $22(50 \%)$ & $5(45 \%)$ & NS \\
Family history & $27(69 \%)$ & $31(70 \%)$ & $8(72 \%)$ & NS \\
BMI (kg/m $\left.{ }^{2}\right)$ & $28.0 \pm 2.8$ & $27.0 \pm 3.3$ & $26.9 \pm 2.0$ & NS \\
HbA1c (mg/dL) & $6.5 \pm 1.2$ & $6.2 \pm 1.2$ & $6.3 \pm 1.1$ & NS \\
LDL (mg/dL) & $115.3 \pm 34.7$ & $115.3 \pm 31.3$ & $104.1 \pm 32.4$ & NS \\
T. chol/HDL (mg/dL) & $4.7 \pm 1.2$ & $4.8 \pm 1.6$ & $4.3 \pm 0.6$ & NS
\end{tabular}

LDL indicates low density lipoprotein cholesterol; T. chol, total cholesterol; and HDL, high density lipoprotein cholesterol.

Table III. Properties of Target Vessels and Stents for Genotypic Subgroups in Patients With CAD

\begin{tabular}{lrrrc}
\hline & DD $(n=39)$ & ID $(n=44)$ & II $(n=11)$ & $P$ \\
\hline RVD $(\mathrm{mm})$ & $3.0 \pm 0.2$ & $3.0 \pm 0.2$ & $3.1 \pm 0.3$ & NS \\
LL $(\mathrm{mm})$ & $12.0 \pm 3.9$ & $10.6 \pm 2.9$ & $11.6 \pm 3.7$ & NS \\
SD (mm) & $3.0 \pm 0.2$ & $3.0 \pm 0.2$ & $3.1 \pm 0.2$ & NS \\
\hline
\end{tabular}

RVD indicates reference vessel diameter; LL, length of lesion; and SD, stent diameter.

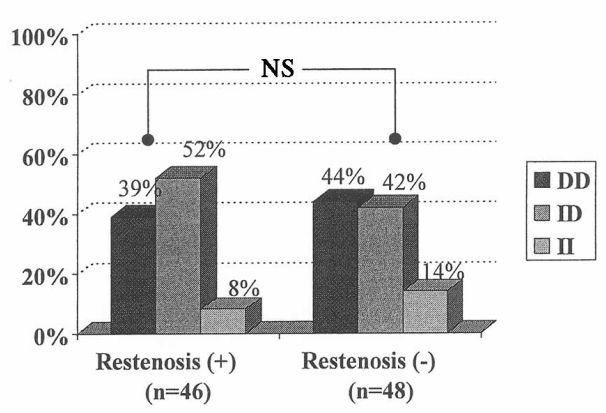

Figure 2. Relationship between restenosis and ACE gene I/D polymorphism.

the relationship between restenosis and ACE gene I/D polymorphism was investigated, no significant difference was found among the genotypic subgroups for restenosis (Figure 2). 


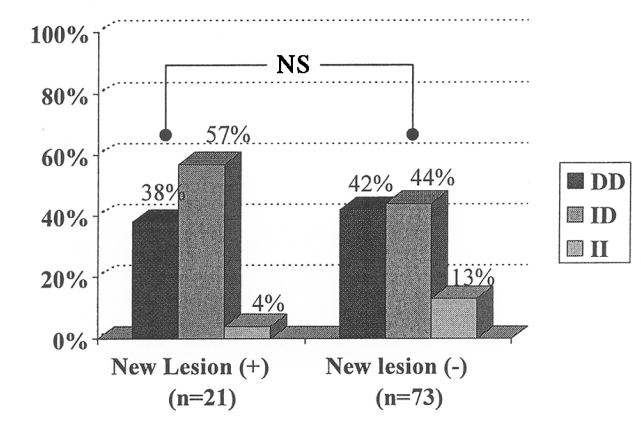

Figure 3. Relationship between ACE gene I/D polymorphism and development of new lesions.

Table IV. Relationship Between ACEI Use and Restenosis in Patients With D Allele

\begin{tabular}{lccc}
\hline Patients with D allele & ACEI $(+)(n=62)$ & ACEI $(-)(n=21)$ & $P$ \\
\hline Restenosis (+) & $27(43.5 \%)$ & $15(71.4 \%)$ & $<0.05$ \\
Restenosis (-) & $35(56.5 \%)$ & $6(28.6 \%)$ & $<0.05$ \\
\hline
\end{tabular}

Development of a new lesion was determined in $21(22.3 \%)$ patients in the $6^{\text {th }}$ month control QCA. The mean percentage of diameter stenosis of the new lesions was $58.3 \% \pm 7.4$. There was no significant difference among the genotypic subgroups concerning the development of a new lesion (Figure 3 ).

In homozygote II patients, both groups with and without restenosis were comparable with respect to ACEI use $(P=0.302)$. However, a significant relationship was determined between restenosis and ACEI use in patients with the D allele (Table IV). HT was comparable in two groups with and without ACEI administration [57 (91.9\%) patients with HT in ACEI (+) group versus 18 $(85.7 \%)$ patients with HT in ACEI (-) group, $P=0.684]$. Additionally, the number of DD and ID patients administered ACEI was comparable for restenosis [12 (38.7\%) DD patients had restenosis versus 15 (48.3\%) ID patients had restenosis $P=0.608]$. ACEI treatment in diabetic patients with D allele decreased stent restenosis significantly in the long-term.

\section{DISCUSSION}

Several previous studies have reported a relationship between ACE gene I/ D polymorphism and various cardiovascular pathologies such as left ventricular 
hypertrophy, ${ }^{16)}$ myocardial infarction, ${ }^{17)}$ dilated cardiomyopathy, ${ }^{18)}$ and target organ damage due to hypertension. ${ }^{19)}$ Both plasma and tissue ACE concentrations appear to be under genetic control. Left ventricular ACE activity is higher in individuals with the D allele, ${ }^{20)}$ and conversion of angiotensin II from angiotensin I is greater in patients with the DD genotype, ${ }^{21,22)}$ indicating higher vascular tissue $\mathrm{ACE}$ activity in the presence of the D allele. Furthermore, upregulation of vascular ACE activity occurs in atherosclerosis. ${ }^{23)}$ However, we did not determine the relationship between ACE gene polymorphism and CAD in diabetic patients. This result may be due differences in risk factors among group 1 and group 2. On the other hand, although risk factors were not different among genotypic subgroups, new lesion development was not related to ACE gene polymorphism.

Neointimal hyperplasia, rather than lumen narrowing by arterial remodeling, prevails in the restenotic process after placement of stents in coronary arteries. ${ }^{24)}$ The renin-angiotensin-aldosterone system has been implicated in the pathogenesis of neointimal hyperplasia, and a role for angiotensin II in the migration and proliferation of vascular smooth muscle cells in restenotic lesions has been proposed ${ }^{25}$ Subjects with the DD genotype of the ACE gene exhibit significantly higher angiotensin II levels and ACE activities as compared with individuals with the II or ID genotype, ${ }^{9,11)}$ suggesting a higher risk of restenosis for carriers of the DD genotype. The potential influence of the I/D genotype on restenosis after percutaneous coronary interventions has been the focus of several studies. ${ }^{24,26,27)}$ Several reports suggested an augmented risk of in-stent restenosis among carriers of the DD genotype. ${ }^{24,28)}$ In our study, we did not find any relationship between ACE gene polymorphism and stent restenosis. The rate of stent restenosis in patients with DD was similar to that in other genotypic subgroups. As the present study was not a placebo controlled study, ACEI use may have reduced the stent restenosis in the DD group.

Werner, et al found no relationship between ACEI and restenosis in patients with the DD genotype of the ACE gene. ${ }^{28)}$ Meurice, et al, ${ }^{29)}$ Jorgensen, et al ${ }^{30)}$ and Ribichini, et al $^{31)}$ suggested ACEI had an unfavorable effect on the restenotic process after coronary stent implantation in patients with the DD genotype. In contrast, we found ACEI had beneficial effects on restenosis in patients with the D allele. Our study population was different from previous studies as all of our patients were type 2 diabetics. However, we did not have a placebo control group, and our patients received various ACE inhibitor drugs. We cannot exclude the possibility that this may have influenced the results of the present study, although a drug-specific rather than a class-specific interaction with the $\mathrm{D}$ allele is unlikely.

Conclusion: ACE gene polymorphism may be effective in the pathogenesis of several diseases via the levels of plasma and tissue ACE. However, we found 
there was no relationship between ACE gene I/D polymorphism and CAD and stent restenosis and new lesion development in diabetic patients. On the other hand, ACEI treatment reduced stent restenosis significantly in type 2 diabetic patients with the D allele (DD or ID). In contrast to previous reports, the results suggest that diabetic patients treated with ACEI who carry the D allele may not have an increased risk of stent restenosis.

Study limitations: Only $72.3 \%$ of diabetic patients after stent replacement had control coronary angiography after 6 months, while the remaining $27.7 \%$ who did not have control angiography had neither symptoms nor coronary ischemia in exercise testing. The trial was not a placebo-controlled randomized study for the use of ACEI. However, it is very difficult to design such a study because ACEI are used frequently in CAD patients. The total number of patients was not large enough to make precise conclusions with respect to ACEI treatment. The patients were treated with various types of ACE inhibitors.

\section{REFERENCES}

1. Elezi S, Kastrati A, Pache J, et al. Diabetes mellitus and the clinical and angiographic outcome after coronary stent placement. J Am Coll Cardiol 1998; 32: 1866-73.

2. Rensing BJ, Hermans WR, Vos J, et al. Luminal narrowing after percutaneous transluminal coronary angioplasty. A study of clinical, procedural and lesional factors related to long-term angiographic outcome. Coronary Artery Restenosis Prevention on Repeated Thromboxane Antagonism (CARPORT) Study Group. Circulation 1993; 88: 975-85.

3. Weintraub WS, Kosinski AS, Brown CL 3rd, King SB 3rd. Can restenosis after coronary angioplasty be predicted from clinical variables? J Am Coll Cardiol 1993; 21: 6-14.

4. Carrozza JP Jr, Kuntz RE, Levine MJ, et al. Angiographic and clinical outcome of intracoronary stenting: immediate and long-term results from a large single-center experience. J Am Coll Cardiol 1992; 20: 328-37.

5. Kastrati A, Schomig A, Elezi S, et al. Predictive factors of restenosis after coronary stent placement. J Am Coll Cardiol 1997; 30: 1428-36.

6. Fischman DL, Leon MB, Baim DS, et al. A randomized comparison of coronary-stent placement and balloon angioplasty in the treatment of coronary artery disease. Stent Restenosis Study Invetigators. N Engl J Med 1994; 331: 496-501.

7. Abizaid A, Kornowski R, Mintz GS, et al. The influence of diabetes mellitus on acute and late clinical outcomes following coronary stent implantation. J Am Coll Cardiol 1998; 32: 584-9.

8. Schelling P, Fischer H, Ganten D. Angiotensin and cell growth: a link to cardiovascular hypertrophy? J Hypertens 1991; 9: 3-15.

9. Rigat B, Hubert C, Alhenc-Gelas F, Cambien F, Corvol P, Soubrier F. An insertion/deletion polymorphism in the angiotensin I-converting enzyme gene accounting for half of the variance of serum enzyme levels. J Clin Invest 1990; 86: 1343-6.

10. Pratt RE, Dzau VJ. Pharmacological strategies to prevent restenosis: lessons learned from blockade of the renin-angiotensin system. Circulation 1996; 93: 848-52.

11. Tiret L, Rigat B, Visvikis S, et al. Evidence, from combined segregation and linkage analysis, that a variant of the angiotensin I-converting enzyme (ACE) gene controls plasma ACE levels. Am J Hum Genet 1992; 51: 197-205.

12. Yusuf S, Sleight P, Pogue J, Bosch J, Davies R, Dagenais G. Effects of an angiotensin-converting-enzyme inhibitor, ramipril, on cardiovascular events in high-risk patients. The Heart Outcomes Prevention Evaluation Study Investigators. N Engl J Med 2000; 342: 145-53. 
13. Fox KM. European trial on reduction of cardiac events with perindopril in stable coronary artery disease investigators. Efficacy of perindopril in reduction of cardiovascular events among patients with stable coronary artery disease: randomised, double-blind, placebo-controlled, multicentre trial (the EUROPA study). Lancet 2003; 362: 782-8.

14. American Diabetes Association. Diagnosis and classification of diabetes mellitus. Diabetes Care 2004; 27 (Suppl. 1): S5-10.

15. Rigat B, Hubert C, Corvol P, Soubrier F. PCR detection of insertion/deletion polymorphism of the human angiotensin converting enzyme gene (DCP1). Nucleic Acids Res 1992; 20: 1433.

16. Schunkert H, Hense HW, Holmer SR, et al. Association between a deletion polymorphism of the angiotensin converting-enzyme gene and left ventricular hypertrophy. N Engl J Med 1994; 330: 1634-8.

17. Ludwig E, Cornelli PS, Anderson JL, Marshall HW, Lalouel JM, Word RH. Angiotensin-converting enzyme gene polymorphism is associated with myocardial infarction but not with development of coronary stenosis. Circulation 1995; 91: 2120-4.

18. Raynolds MV, Bristow MR, Bush EW, et al. Angiotensin-converting enzyme DD genotype in patients with ischaemic or idiopathic cardiomyopathy. Lancet 1993; 342: 1073-5.

19. Baris N, Ozerkan F, Onder MR, et al. Relationship between angiotensin converting enzyme gene polymorphism and number of target organ damage in essential hypertension. Türk Kordiyolgi Dernegi Arsivi 2004; 32 : 107-14.

20. Danser AH, Schalekamp MA, Bax WA, et al. Angiotensin-converting enzyme in the human heart. Effect of the deletion/insertion polymorphism. Circulation 1995; 92: 1387-8.

21. Buikema H, Pinto YM, Rooks G, Grandjean JG, Schunkert H, van Gilst WH. The deletion polymorphism of the angiotensin-converting enzyme gene is related to phenotypic differences in human arteries. Eur Heart $\mathbf{J}$ 1996; 17: 787-94.

22. Ueda S, Elliott HL, Morton JJ, Connell JM. Enhanced pressor response to angiotensin I in normotensive men with the deletion genotype (DD) for angiotensin-converting enzyme. Hypertension 1995; 25: 1266-9.

23. Diet F, Pratt RE, Berry GJ, Momose N, Gibbons GH, Dzau VJ. Increased accumulation of tissue ACE in human atherosclerotic coronary artery disease. Circulation 1996; 94: 2756-67.

24. Hoffmann R, Mintz GS, Dussaillant GR, et al. Patterns and mechanisms of in-stent restenosis. A serial intravascular ultrasound study. Circulation 1996; 94: 1247-54.

25. Pratt RE, Dzau VJ. Pharmacological strategies to prevent restenosis: lessons learned from blockade of the renin-angiotensin system. Circulation 1996; 93: 848-52.

26. Amant C, Bauters C, Bodart JC, et al. D allele of the angiotensin I-converting enzyme is a major risk factor for restenosis after coronary stenting. Circulation 1997; 96: 56-60.

27. Ryu SK, Cho EY, Park HY, et al. Renin-angiotensin-aldesterone system (RAAS) gene polymorphism as a risk factor of coronary in-stent restenosis. Yonsei Med J 2002; 43: 461-72.

28. Koch W, Mehilli J, von Beckerath N, Bottiger C, Schomig A, Kastrati A. Angiotensin I-converting enzyme (ACE) inhibitors and restenosis after coronary artery stenting in patients with the DD genotype of the ACE gene. J Am Coll Cardiol 2003; 41: 1957-61.

29. Meurice T, Bauters C, Hermant X, et al. Effect of ACE inhibitors on angiographic restenosis after coronary stenting (PARIS): a randomised, double-blind, placebo-controlled trial. Lancet 2001; 357: 1321-4.

30. Jorgensen E, Kelbaek H, Helqvist S, et al. Predictors of coronary in-stent restenosis: importance of angiotensinconverting enzyme gene polymorphism and treatment with angiotensin-converting enzyme inhibitors. J Am Coll Cardiol 2001; 38: 1434-9.

31. Ribichini F, Wijns W, Ferrero V, et al. Effect of angiotensin-converting enzyme inhibition on restenosis after coronary stenting. Am J Cardiol 2003; 91: 154-8. 